\title{
Conceptual design of lightweight structures: the role of morphological indicators and the structural index
}

\author{
W. P. De Wilde \\ Department of Mechanics of Materials and Constructions (MeMC), \\ Vrije Universiteit Brussel, Brussels
}

\begin{abstract}
Firstly, but in no way exclusively, this paper addresses architectural engineers facing critical design decisions in the phase of so-called "conceptual design". The resulting design must yield a structure showing a sound behaviour in both the serviceability limit state (SLS) and in the ultimate limit state (ULS), also meaning that three essential criteria should be satisfied: strength, stiffness and stability (the latter including, if relevant, an acceptable dynamic behaviour). However, the question very often remains open as to which of the three criteria is overruling the other ones. This paper, a synthesis of the work of a research group headed by the author, tries to show that a conceptual design methodology can be developed, hereby using the concept of morphological indicators (originally developed by P. Samyn, subsequently P. Latteur and within the research group) and a structural index (introduced by Shanley). This methodology also gives an answer to the question that very often arises when designing lightweight structures: "design for strength" or "design for stiffness"? Examples in subsequent papers, presented during this Conference and thus included in these Proceedings, illustrate the methodology nowadays used by our students in architectural engineering when designing and analysing their structures.

Keywords: conceptual design of architectural structures, strength, stiffness, structural stability, structural vibrations.
\end{abstract}

\section{Morphological indicators}

The so-called morphological indicators (MI) were introduced by P. Samyn [1] in 1999. As different papers, both within this conference and in other journals and 
books (see e.g. a more recent book of P. Samyn [2]), have already or will underline(d) the potentials of these dimensionless numbers, and thus we will restrict ourselves to a very short introduction.

P. Samyn essentially introduced two indicators, one related to the minimum volume of material required for a structural typology achieving a fully stressed design, the other related to the maximum displacement in the same structure. The combination of those two indexes, being the volume indicator $\mathrm{W}$ and the displacement indicator $\Delta$ allow the designer to select not only a (sub)optimal typology but also its optimal aspect ratio.

The indicators are dimensionless numbers, function of very few parameters, the most important being the so-called slenderness of the structure $\mathrm{L} / \mathrm{H}$, in which $\mathrm{L}$ is the larger and $\mathrm{H}$ the lesser dimension of a window, framing the structure.

P. Samyn defined them as:

a) $\mathrm{W}=\frac{\sigma \mathrm{V}}{\mathrm{FL}}$, in which $\sigma$ is the admissible stress (in practice we consider the allowable stress in the serviceability limit state (SLS), V the volume of material, $\mathrm{F}$ the resultant of (static) forces, loading the structure, and L its span.

b) $\Delta=\frac{\mathrm{E} \delta}{\sigma}$, in which $\mathrm{E}$ is the elastic modulus and $\delta$ the maximum displacement.

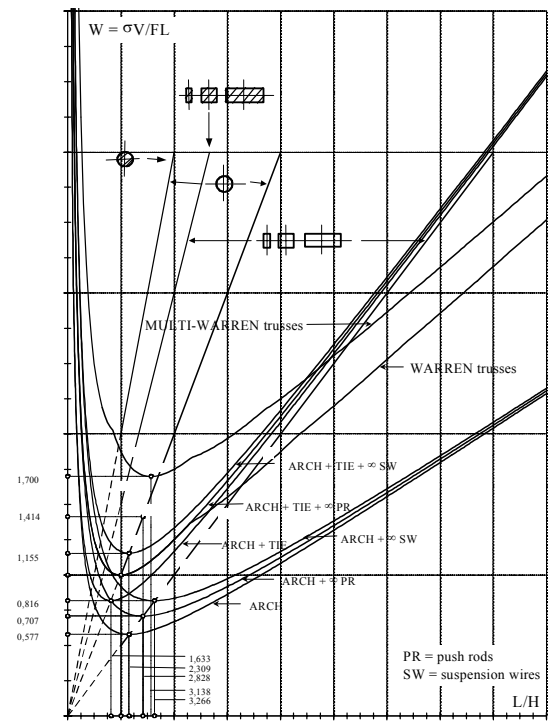

Figure 1.

He also shows that they can be expressed as a function of $\mathrm{L} / \mathrm{H}: \mathrm{W}=\mathrm{W}(\mathrm{L} / \mathrm{H})$ and $\Delta=\Delta(\mathrm{L} / \mathrm{H})$. This allows one to draw, either analytically or numerically, diagrams showing the values of the indicators in function of the slenderness, for 
different typologies of structures. The recent book of P. Samyn [2], although not exhaustive, contains an impressive amount of typologies that can be compared: see fig. 1 as an example of a comparison of different typologies through the volume indicator: this diagram is taken from [9]. Similar graphs were developed for the displacement indicator $\Delta$.

It is clear that P. Samyn - see the title of his thesis - hereby provided the architect with " a tool allowing to reach a suboptimal design at the stage of the conceptual design". The fact that he is still using it today, and undoubtedly producing designs of outstanding quality, proves the robustness of the tools he introduced.

However, two major objections could be foreseen and they were very soon subject of controversy. Indeed, the two indicators allow for a preliminary design, achieving the required performances of strength and stiffness with a minimum volume of material (a fully stressed design of statically determinate structures, subject to classical load cases)...but what about (in)stability? It is clear that, in its most simple form, the developed method does not take - at least explicitly - into account possible buckling phenomena. However it would be unjust to consider that it completely overlooks the existence of this phenomenon: in both [1] and (more detailed) in [2], P. Samyn shows that "correction factors" can be computed, thus defining an increase of material consumption, and trying to control the stability of the equilibrium.

Nevertheless, gradually we were convinced that conceptual design should take into account the totality of the criteria to be satisfied by the structure:

- the strength of the structural parts is controlled through the indicator of volume: $\mathrm{W}=\frac{\sigma \mathrm{V}}{\mathrm{FL}}$, as it starts from a fully stressed design (at a stress level $\sigma$ ). In the conceptual design stage, a minimal value of this indicator is aimed at, thus trying to achieve a minimal consumption of material. But, as we shall experience very quickly, a mere choice of the slenderness $\mathrm{L} / \mathrm{H}$, corresponding to a minimum of the curve for the chosen typology (see e.g. fig.1) does not solve the problem! The reason is simple: this simple minimisation does not take into account the stiffness, stability...and dynamic requirements of the design. In this sense we could say that each of the three other criteria introduce kinds of "forbidden zones" in the $\mathrm{W}=\mathrm{W}(\mathrm{L} / \mathrm{H})$ diagrams: a forbidden zone for the excessively flexible structures, one for the unstable structures and a last one - if relevant - for the unacceptable vibrations.

- the stiffness of the structure is evaluated through the indicator of displacement: $\Delta=\frac{\mathrm{E} \delta}{\sigma \mathrm{L}}$. As one can see, it is proportional to the ratio $\delta / \mathrm{L}$, which is generally limited by design codes (see e.g. Eurocodes). As we will show later this indicator, originally introduced by P. Samyn will be of primordial importance when evaluating the risk for resonance of a structure. 
- through the buckling indicator $\Psi=\frac{\mu \sigma \mathrm{L}}{\sqrt{\mathrm{qEF}}}$, introduced by Latteur [3], in which $\mu$ is the length reduction factor (due to end conditions of the elements), and $q=\frac{1}{\Omega^{2}}$ in which $I$ is the (minimal) inertia moment of the section and $\Omega$ its section, one can evaluate the sensitivity of the structure to (local) buckling: the higher $\Psi$, the higher the risk. We are convinced that this instrument should be used in conjunction with the other $(W, \Delta, \Theta)$, as it gives a better estimate of the penalty in material consumption than the correction factors used by P. Samyn. To be mentioned is that J. Van Steirteghem shows in his thesis work [10] that one can evaluate the risk for global instability, starting from this indicator.

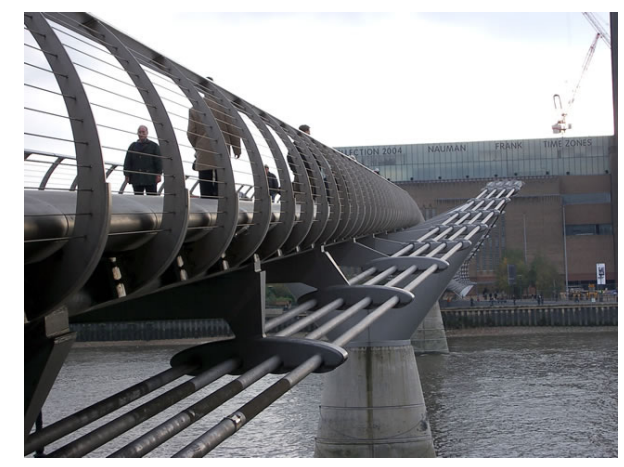

Figure 2.

Eventually one also has to consider an indicator describing the dynamic behaviour of the structure. This is achieved through the use of the indicator of the first natural frequency $\Theta=\frac{1}{\sqrt{\Delta}}=\mathrm{f}\left(\frac{\mathrm{L}}{\mathrm{H}}, \Psi\right)$, extensively discussed by J. Van Steirteghem in [10]. As one sees, there is a direct link with the indicator of displacement $\Delta$. This indicator $\Theta$ is also directly dependent on the buckling indicator, which is not surprising: both resonance and buckling phenomena in elastic systems are related with transformation of energy (compression into bending or torsion for buckling, potential into kinetic for resonance). An important observation can be made here: if one accepts all the simplifications introduced by the concept of morphological indicators and if one has a closer look at the indicator $\Theta$, one will notice that it is independent on the volume indicator and thus on the mass of the system. This could bring one to the conclusion that - at least, at the stage of conceptual design - there is little hope that one can improve the dynamic behaviour of the structure through simple 
addition of mass. This has been confirmed when designing e.g. slender and elegant footbridges: one quickly comes to the conclusion that the penalty in mass, in order to achieve an acceptable spectrum of resonance frequencies is (very) much higher than the one necessary to control its buckling behaviour (see e.g. [10]).

A very well known example, proving this observation, is the $350 \mathrm{~m}$ long Millennium Bridge, designed by Sir Norman Foster in collaboration with Arup Ltd. See e.g. http://www.arup.com/millenniumbridge/, site from which we quote: “...There are two fundamental ways to limit dynamic excitation:

* Stiffen the structure, so the frequency of the bridge and our footsteps no longer match;

* Add damping to absorb the energy.

It was concluded that stiffening the bridge to change its frequency was not a feasible option. The bridge would need to be at least tenfold stiffer laterally to move its frequency out of the excitation range. The additional structure required to do this would dramatically change the appearance of the bridge.

It was decided to adopt a damping solution, either active damping or passive damping. Active damping uses powered devices to apply forces to the structure to counteract vibrations. Passive damping relies on harnessing the movements of the structure to absorb energy." (end of quote).

This is only one of the many examples proving that one has to give necessary attention to the dynamic behaviour of lightweight structures, if one wants to design an acceptable lightweight structure! But this also proves that solving the problem with addition of mass and/or stiffness is very seldom the best option. A new challenge thus for designers!

\section{2 "Design for stiffness" versus "design for strength"}

If one wants to consume a minimum of material it is logical that he follows a strategy by which the indicator of volume $\mathrm{W}$ is set as the hierarchically most important. Given a span L, loads $\mathrm{F}$ and material properties (among which $\sigma$ controls $\mathrm{W}$ and $\mathrm{E}$ controls $\Delta$ ) one can select an acceptable slenderness $\mathrm{L} / \mathrm{H}$ and thus $\mathrm{H}$ for a chosen typology of structure. As P. Samyn very rightly points out in [2], one can take into account the stiffness and even the stability requirements, although one can argue that the latter requirement is addressed in a somewhat empirical way.

However, from our experience and research in the Vrije Universiteit Brussel, it appears that:

- the strategy, putting forward the indicator of volume $\mathrm{W}$ as objective function, although yielding performing and lightweight preliminary designs, practically always produces solutions that have to be corrected in order to satisfy the remaining requirements. As the objective is to minimise volume, one very often achieves designs which are too flexible, unstable....and, most of all, dynamically unacceptable.

- it would be good to think about the strategy that consists in an a priori selection of the indicator that should be selected as the hierarchically 
more important: $\mathrm{W}$ versus $\Delta$, or strength versus stiffness. This alternative is also linked to the two analyses in serviceability limit state (SLS) and ultimate limit state (ULS). In fact, one quickly gets a feeling that there are two extreme situations: on one hand the heavy and very stiff structures (e.g. masonry bridges [11]), on the other hand the lightweight and often rather flexible structures (e.g. the modern footbridge, cf. Millennium Bridge in London). The experience acquired during studio work with architectural engineers, who have to design structures of all types, covering a wide spectrum of functionalities and spans, has underlined that a measure of the danger for (= sensitivity to) instability phenomena (both buckling and resonance) is the best guide for the choice between "design for strength" and "design for stiffness".

- other empirical observations are important:

○ when one foresees risks for instability phenomena it is better to approach the problem through "design for stiffness".

o when designing lightweight structures it is almost always the design constraints in the SLS that prevail over those for the ULS. In other words, these constructions have an enormous reserve in strength, and they thus show a much higher value of $\mathrm{W}$ than the optimal one!

○ the penalty imposed by additional material consumption, in order to avoid unacceptable vibrations, is much more severe than the one controlling (in)stability.

- one could thus look for a kind of "separation line" or a criterion allowing the selection of the adequate strategy. It seems also that, in order to take into account the "scale effects", it is better to look for a parameter which takes into account the absolute value of both span $\mathrm{L}$ and forces $\mathrm{F}$ (hereby included the permanent forces on and self-weight of the structure). Van Steirteghem, in his $\mathrm{PhD}$ work [10], suggests that this parameter could be $L / \sqrt{F}$, which in fact has been introduced by Shanley [8], who called the inverse of its square $\left(\mathrm{F} / \mathrm{L}^{2}\right)$ the "structural index". Large values point to large span structures with relatively low permanent loads, small values to the contrary. In another paper, here presented, he will show the role played by the structural index in some structural choices. This choice is by no means arbitrary as the indicators for buckling $\Psi$ and for the first resonance frequency $\Theta$ can both be linked to it: the former $\Psi$ even explicitly, as it is proportional to the structural index, the latter being an implicit function of $\Psi$.

This brings us to an important conclusion: at the stage of conceptual design one should in the first place check which of the two design strategies, being "design for strength" versus "design for stiffness" should be adopted. A reasonable indication can be obtained by the analysis of the mentioned morphological indicators, but most of all by the structural index. The latter will direct you to a design in SLS rather than ULS, if risks for buckling and/or resonance are to be dealt with. 


\section{Alternate strategies}

Probably one of the most challenging and promising alternatives to the design strategy described in the previous sections consists in the use of "new algorithms", allowing a search for improved typologies, especially in the case of complicated load conditions. Instead of looking for the optimal typology of structure, given the span L and the loads F, which yields an optimal slenderness $\mathrm{L} / \mathrm{H}$ for the catalogued typology (e.g. a Warren truss), one can "open the search space" to yet unknown typologies. This can be achieved using e.g. genetic algorithms, evolutionary strategies, etc. Verbeeck et al. show in [14] that genetic algorithms can be very powerful tools in optimisation processes, but above all have shown in [15] that they can yield new, often unsuspected, typologies, better suited for the given problem. Important is to mention that the objective function these algorithms try to minimize is the volume indicator $\mathrm{W}$, the other morphological indicators reducing the search space by inducing side constraints.

\section{Preliminary conclusions}

As will be shown by Vandenbergh et al. [12] in a subsequent paper, the conceptual design of lightweight structures introduces the need for an a priori selection of a design strategy based on the need to satisfy in the first place a SLS or an ULS. This can be achieved through an adequate use of morphological indicators, among which the structural index is also important: it is the only one taking into account the so-called scale effects. J. Van Steirteghem has convincingly shown in his Ph.D thesis [10] that it is of paramount importance to include the buckling indicator as a full partner when designing structures subject to dominant static loads. As the buckling indicator is directly related to the structural index, it immediately gives indications about the limit state, either SLS or ULS, in which the structure should be calculated. This choice also is linked to the alternative between "design for stiffness" and "design for strength".

The result of the minimisation of the volume indicator $\mathrm{W}$, in an acceptable design subspace, and in which the two other morphological indicators $\Delta$ and $\Psi$ introduce side constraints, combined with the eagerness of modern architects to show their ability to cross very large spans, very often yields designs of structures showing an unacceptable dynamic behaviour. The penalty induced by corrections on mass or stiffness practically always affects the optimum value of $\mathrm{W}$ in a much more severe way than e.g. the need to satisfy buckling or stiffness requirements. Ponsaert et al. [13] will show that the unacceptable vibrations can be controlled through active, hybrid or passive damping, rather than through the tuning of stiffness and/or mass.

Although it is perhaps a little early to make final statements, I strongly suspect that the direction taken by my student B. Verbeeck in the field of new numerical algorithms will yield interesting results. It is indeed quite logical to think that, as long as you restrict your search for a minimum volume structure 
within a given set of typologies, you could miss better solutions! I am thus convinced that there is still an open field and want to explore it.

I am quite thrilled by the enthusiasm of the students who discover the potentials of these indicators and indexes, when working for their studio work. At least it proves that it can effectively be used at the stage of conceptual design. And was that not the goal one tries to achieve as a teacher of structural design?

\section{Acknowledgements}

Scientific research is very rarely the output of a single brain, and it has not been different with the present study. I thus want to pay due respect to colleagues and students. In the first place, two very important contributors to my evolving insights in structural design and analysis: Philippe Samyn, eminent architect and engineer, and Pierre Latteur, a structural engineer with a real feeling for structural behaviour. They triggered my interest for morphological indicators, allowing me to direct several theses at both Master's and Doctoral level. All of the others will recognise themselves, but I want to underline the outstanding research work of Jan Van Steirteghem, architectural engineer, who sort of "filled some gaps" left by the excellent work of P. Samyn and P. Latteur, and also initiated work in the field of dynamics of lightweight structures: he allowed me to come back to my real passion for structural vibrations.

During the last years I have been also collaborating with one of my former students, Marijke Mollaert, who finished her Ph.D in 1984 on tensile structures and, since then, has become a colleague and always has remained a close friend. I still spend a lot of time discussing new ideas with her and her students, all of them involved in this exciting field of form-active tensile structures. Although the discipline of designing these structures is very much different from what we are doing in my research group, the ideas one can pick up during those informal meetings are refreshing and really exhilarating. Thank you, Marijke, for your friendship.

WIT Conferences were also regular meeting points, confronting me with new ideas and insights: first CADCOMP, later evolving into these HPSM Conferences, OPTI, but also Structural Repair and Maintenance of Historic Structures. In particular, I want to mention my friends Santiago Hernandez (U of La Coruña, Spain) and Jerry Connor (MIT, USA), with whom it is an enlightening experience to discuss all kinds of matters, even structures!

Research needs funding and scholarships and I thus also want to acknowledge the Institutions which helped this research financially: Fund for Scientific Research in Flanders (FWO), Fund for Applied Research in Flanders (IWT), the VUB and several industrial partners.

Last but not least a personal word of gratitude for Carlos A. Brebbia, always showing more confidence in my skills than I deserve, and allowing me to meet such fine persons within the Board of Directors of WIT. It is now about 35 years that we met for the first time and it is always with extreme pleasure that we see each other, either in the Lodge or at his Conferences. 


\section{References}

[1] Samyn, P., Etude comparée du volume et du déplacement de structures bidimensionnelles, sous charges verticales entre deux appuis - vers un outil d'évaluation et de prédimensionnement des structures (4 vol.), Ph. D. thesis, Université de Liège, 1999.

[2] Samyn, P., Étude de la morphologie des structures à l'aide des indicateurs de volume et de déplacement, Académie royale de Belgique, Classe des Sciences (2004), ISBN 0365-0952.

[3] Latteur, P., Optimisation des treillis, arcs, poutres et câbles sur base d'indicateurs morphologiques - application aux structures soumises en partie ou en totalité au flambement (3 vol.), Ph. D. thesis, Vrije Universiteit Brussel, 2000.

[4] Schlaich, J., Bergermann, R., Leicht Weit, Light Structures, Prestel (München, Germany), ISBN 3-7913-2918-9, 2005.

[5] Latteur P., Samyn P. et De Wilde P., 2001, Optimization des arcs paraboliques et en chaînette - aide à la conception sur base d'indicateurs morphologiques. Revue française de Génie Civil, Vol. 5, $\mathrm{n}^{\circ} 1$.

[6] Latteur P., Samyn P., De Wilde P., 2000, Comparaison des treillis classiques type Warren, Pratt et Howe : optimization et prédimensionnement sur base d'indicateurs morphologiques. Revue française de Génie civil, Vol. 4, ${ }^{\circ} 4$.

[7] Shea K., 1997, Essays of Discrete Structures: purposeful design of grammatical structures by direct stochastic search, $\mathrm{PhD}$ Thesis, Carnegie Mellon University, USA.

[8] Shanley FR. Weight-Strength Analysis of Aircraft Structures. New York: Dover, 1960.

[9] Samyn P., Latteur P., Van Vooren, J., Volume of structures: application to classical and harmonic structures, International IASS symposium on Lightweight structures in Architecture, Engineering and Construction, 1998 -October 5-9, Sydney, Australia.

[10] Van Steirteghem J., A Contribution to the Optimisation of Structures Using Morphological Indicators: (In)Stability and Dynamics, Ph.D. thesis, Vrije Universiteit Brussel, Mechanics of Materials and Structures, W.P. De Wilde, supervisor, 2006.

[11] Audenaert A., Peremans H., De Wilde W.P., Static determination of the internal forces and displacements in arch bridges, Masonry Society Journal, vol.22, $\mathrm{n}^{\circ} 1$, pp.97-111, September 2004.

[12] Vandenbergh Th., Van Steirteghem J., De Wilde W. P., Samyn P., Influence of stiffness constraints on optimal design of trusses using morphological indicators, HPSM 2006, Wit Press, 2006.

[13] Ponsaert W., De Wilde W. P., Samyn P., Van Steirteghem J., The use of tuned mass dampers in beam structures, HPSM 2006, WIT Press, 2006.

[14] Verbeeck B, De Wilde WP, Samyn Ph, Van Steirteghem J., The Use of Genetic Algorithm and Morphological Indicators in the Optimization of 2D Trusses, HPSM 2004, Wit Press, 2004. 
12 High Performance Structures and Materials III

[15] Verbeeck B., Van Steirteghem J., De Wilde W.P., Samyn Ph., The Need of Numerical Techniques for the Optimization of Structures Using Morphological Indicators, Proceedings OPTI2005, WIT Press, 2005. 